\title{
Population Focused Nursing: Advocacy for Vulnerable Populations in an RN-BSN Program
}

\author{
Melissa Jones \\ Linfield College - Portland Campus Nursing \& Online and Continuing Education \\ Paul Smith \\ Linfield College - Portland Campus
}

Follow this and additional works at: https://digitalcommons.linfield.edu/nursfac_pubs

Part of the Nursing Commons, and the Online and Distance Education Commons

\section{DigitalCommons@Linfield Citation}

Jones, Melissa and Smith, Paul, "Population Focused Nursing: Advocacy for Vulnerable Populations in an RN-BSN Program" (2014). Faculty Publications. Accepted Version. Submission 6.

https://digitalcommons.linfield.edu/nursfac_pubs/6

This Accepted Version is protected by copyright and/or related rights. It is brought to you for free via open access, courtesy of DigitalCommons@Linfield, with permission from the rights-holder(s). Your use of this Accepted Version must comply with the Terms of Use for material posted in DigitalCommons@Linfield, or with other stated terms (such as a Creative Commons license) indicated in the record and/or on the work itself. For more information, or if you have questions about permitted uses, please contact digitalcommons@linfield.edu. 
Population Focused Nursing: Advocacy for Vulnerable Populations in an RN-BSN Program 


\begin{abstract}
The purpose of this article is to describe an innovative learning activity for online RN-BSN students designed to foster advocacy for vulnerable populations. The Vulnerable Population Advocacy Assignment, included as a component of the online Population-Focused Nursing class, provides students with the opportunity to identify and develop an awareness of issues impacting vulnerable populations and to advocate for policy changes that will influence the health of individuals, families, and populations. RN-BSN students build on previous knowledge and skills in professional communication and advocacy as they develop a policy statement designed to address health disparities impacting local, national, and global populations.

Key words: Advocacy, Nursing Education, Population Focused Nursing, and Vulnerable Populations.
\end{abstract}


The purpose of this article is to describe an innovative learning activity designed to foster advocacy for vulnerable populations in RN-BSN students. The Vulnerable Population Advocacy Assignment is included as part of the Population-Focused Nursing course in a small liberal arts college in the Pacific Northwest. Students take the Population-Focused Nursing course in the second semester of the online RN-BSN program which is focused on exploring public health principles and their application to multicultural, domestic, and global populations. Additionally, the course emphasizes the development of the RN-BSN student as a global citizen in the practice of professional nursing. An outline that includes the main ideas of the article is presented in Table 1.

\section{Background}

The Essentials of Baccalaureate Education for Professional Nursing Practice provides the curricular elements and framework for building the baccalaureate nursing curriculum for the 21st century (American Association of Colleges of Nursing [AACN], 2008). The Essentials document identifies recommendations from key stakeholders and landmark documents such as the Institute of Medicine (IOM) report that addresses the core knowledge required for all healthcare professionals (AACN, 2008).

As defined by the AACN (2008), Baccalaureate Essential I addresses the importance of a liberal education for Baccalaureate Generalist Nursing practice. A liberal education is critical to the generation of responsible citizens in a global society (AACN, 2008). A liberal education provides nursing students with the ability to integrate knowledge, skills, and values from the arts and sciences to provide humanistic, safe quality care, to act as advocates for individuals, families, groups, communities, and/or populations, and to promote social justice (AACN, 2008). 
A liberal education emphasizes the development of leadership skills and a foundation of professional values and standards (AACN, 2008).

\section{Concept Development}

In an effort to deemphasize content and enhance the critical thinking of students, a conceptual approach to the curriculum was implemented (Giddens, Brady, Brown, Wright, Smith, \& Harris, 2009). There are several concepts integrated throughout the RN-BSN curriculum emphasized in this learning activity including advocacy, health policy, leadership, and vulnerable populations.

\section{Advocacy and Leadership}

There are multiple traits and characteristics that are important in the development of professionalism in nursing. Advocacy plays a key role, whether it is for an individual, community, or a population. A focus on an individual or group's rights or best interests is an ethical concept for nursing practice and illustrates a definition of advocacy (Blais \& Hayes, 2011). The American Nurses Association (ANA) (2010a) states that advocacy "is a fundamental aspect of nursing practice” (p. 20). Preparing nurses for leadership in areas of advocacy and policy development allows them to develop a vision for how nurses contribute to creating healthy communities.

\section{Health Policy}

One of the key messages in the Institute of Medicine (2010) report, The Future of Nursing: Leading Change, Advancing Health, includes the idea that "Nurses should be full partners, with physicians and other health professionals, in redesigning health care in the United States" (p. 4). Stanhope and Lancaster (2012) suggested that one of these areas of partnership for nurses is related to policy development. Policy development is a collaborative process that 
involves working with multiple groups and coalitions (Stanhope \& Lancaster, 2012) to improve conditions and health outcomes for individuals, communities, and populations.

\section{Vulnerable Populations}

In the Standards of Practice for Culturally Competent Nursing Care, Douglas, Pierce, Rosenkoetter, Pacquiao, Callister, Hattar-Pollara, Lauderdale, Milstead, Nardi, and Purnell (2011) cited the AACN and the expectation that nurses develop a "commitment to the health of vulnerable populations and the elimination of health disparities" (p. 319). Nurses working in community settings are often highly involved with vulnerable populations (Stanhope \& Lancaster, 2012). The social science and public health literature defines the terms vulnerability and vulnerable populations in a variety of ways depending on the context or program (Hutchins, Truman, Merlin, \& Redd, 2009). For the purposes of this activity, vulnerability is based on inequities in health and healthcare, social status, and risk for disease or illness. Vulnerable populations include individuals living in poverty, those who have immigrant status, people of color, and people who are marginalized by their sexual preference and/or religion (Bailey, 2010). Dorsey and Murdaugh (2003) applied the concept of vulnerability to persons, families, and groups who are non-English speaking, homeless, diagnosed with HIV/AIDS, and high-risk mothers and children. Additionally, Pacquiao (2008) described vulnerable population groups as "those who are not only particularly sensitive to risk factors but also possess multiple cumulative risk factors" (p. 190).

Throughout the Population course and within the context of the Advocacy Assignment, students also gain familiarity with the terms health disparity and social health determinants. The Centers for Disease Control and Prevention (CDC) (2009) defines a health disparity as a type of health difference linked with social or economic disadvantage and social determinants of health 
(SDH) as complex, integrated social and economic systems that are responsible for most health inequities. A thorough understanding of how each of these concepts has been linked to the health of vulnerable populations can assist students to contribute to reducing health disparities.

\section{Community-Based Nursing Education}

The Linfield-Good Samaritan School of Nursing curriculum is grounded in liberal arts education that includes integrative learning, inclusive excellence, and experiential learning. The community-based curriculum reflects the dynamic relationship between global and local communities and the community of learning. Central to this community of learning is a focus on learner centered education, which engages students in the practice of health promotion, illness prevention and treatment and reflects the value of social justice (Linfield College, 2013). The curricular themes of communication, community, diversity, ethics, health, and stewardship provide a foundation for the program's design and are developed throughout the program (Linfield College, 2013).

Prior to taking the Population-Focused Nursing course, RN-BSN students take a Transition course to build on their previous knowledge and skills applicable to the practice of professional nursing. In addition to addressing professional nursing roles of caring, advocacy, and leadership, students engage in learning activities related to community and public health, community health promotion, and disease prevention. Students conduct a thorough assessment of their community and develop an intervention designed to promote health and prevent disease. As students move to the Population course, they begin to develop their practice in nursing from a community-based perspective to a focus on the health of populations. 


\section{Population-Focused Nursing}

A population is a collection of individuals who share one or more personal or environmental characteristic (CDC, 20103; Stanhope \& Lancaster, 2012). Population-focused nursing practice is community oriented, collaborative, inclusive, scientific, and directed toward developing programs and policies within the larger system to address the health needs of the population (Stanhope \& Lancaster, 2012). This particular RN-BSN course explores public health principles and their application to multicultural, domestic, and global populations.

\section{Learning Module}

In the weeks leading up to the Advocacy Assignment, students are exposed to concepts impacting the health of vulnerable populations including global health disparities, social justice, human rights, cultural sensitivity, compassion, professional advocacy, and more. A learning module that focuses on the social determinants of health and global health disparities prepares students to identify a vulnerable population for their advocacy. Students complete assigned reading, participate in web-based activities, watch relevant videos, and participate in collaborative group discussions. In one of the group discussions, students are required to analyze the relationship between social determinants of health, health inequalities, and health outcomes. They are also required to share an example of social and health inequities in their own community and make recommendations for how nurses can contribute to reducing them.

\section{Vulnerable Population Advocacy Assignment}

The Advocacy Assignment is designed to foster advocacy for vulnerable populations in RN-BSN students. The assignment requires students to develop a compelling piece of advocacy for a current issue that impacts the health of a specific vulnerable population in the local, national, or global community. The assignment is written as a policy statement and presented to 
an audience in an effort to persuade them to support the issue. The statement is concise, informative, and designed to address a true disparity in health.

At the start of the assignment, students are required to choose a vulnerable population, address a specific health disparity impacting the population, and identify a target audience in a position to make policy decisions or allocate resources for the population. In the assignment, students are asked to:

1. Identify a vulnerable population and present relevant statistics that demonstrate that a health disparity exists;

2. Describe the impact on health that includes the relevant social, environmental, economic, and cultural issues;

3. Propose specific recommendations to an audience who is in a position of making decisions that make a difference for the specific vulnerable population.

During a recent semester, 58 RN-BSN students completed the Advocacy Assignment. A sampling of the vulnerable populations and required components of the assignment chosen by students is included in Table 2.

Students are expected to utilize epidemiological data to reflect the scope of the issue impacting the population and utilize current evidence in their analysis of the issue. They are required to analyze the relevant social, environmental, economic, and cultural issues influencing short and long term health outcomes for the specific vulnerable population.

The experience of developing recommendations that address a health disparity and presenting these to a specific audience has provided students with the opportunity to improve their skills in professional advocacy. In addition, students choose topics of interest or concern that they have developed within the local, national, or global community. Through their 
advocacy for a specific vulnerable population, students have the opportunity to develop their skills in leadership and collaboration with other organizations to reduce disparities.

\section{Communication}

Effective communication is a critical aspect of advocacy in nursing. Nursing students have many opportunities throughout their educational experiences to begin to "find their voice". The ability to articulate concisely, whether in written or verbal form, can assist the nurse to be more effective in delivering their advocacy.

The second part of the assignment includes presenting their one page statement in the online discussion forum to an assigned partner who is serving as a member of their intended audience. In addition to posting their statement, students are asked to prepare a brief corresponding visual presentation on the topic that would accompany their verbal statement if they were truly presenting this to their identified target audience. Most students choose to use 56 PowerPoint slides to present their advocacy in a concise manner. It is recommended that the visual media include data, statistics, or images that might help persuade their target audience to support their advocacy.

The purpose of the online dialogue and the written statement is to provide students with the chance to practice persuasive communication when they present their policy statement and when they engage in dialogue with their peers. The dialogue takes place in an asynchronous format so students have the ability to thoughtfully consider the advocacy presented by their peers before engaging in discussion. By addressing the identified target audience in a concise manner and by presenting an informative, clear piece of advocacy, students are able to develop their skills in effective, professional communication. Although most students agree with the advocacy that is presented, they are asked to take an opposing view and to support this view with rationale 
and support from the literature. The student who is opposing often has to go against his or her own moral and ethical beliefs to oppose the initial advocacy that is presented. This opposition puts the student in the mind of decision makers (target audience) who may not see the identified advocacy as a true need.

By having the students challenge or reject their assigned partner's statement, and to defend their own original statement with stronger points and more supportive data, the students learn collaboration and increase their knowledge of the needs of vulnerable populations.

Becoming comfortable with conflict and actually being able and willing to seek conflict will allow leaders to truly become agents of change (Grossman \& Valiga, 2009). This activity has the potential to impact the student's ability to articulate their advocacy and communicate in multiple ways.

\section{Leadership on Policy Issues}

As students engage in the assignment, they are learning the necessary skills to apply advocacy to their identified vulnerable population. The Quad Council of Public Health Nursing Organizations (2011) stated that generalist public health nurses are expected to identify policy issues that are relevant and may impact the health of individuals, families, and groups. In Table 3, the student recommended a policy that would create a separate sex education curriculum for the Lesbian, Gay, Bisexual, Transgendered, and Questioning (LGBTQ) high school student.

A statement that sustains nursing's social contract with society is that "public policy and the healthcare delivery system influence the health and well-being of society and professional nursing” (ANA, 2010b, p. 7). One definition of nursing that identified the essential features of professional nursing is that nursing will have "influence on social and public policy to promote social justice" (ANA, 2010b, p. 9). Harkness and DeMarco (2012) stated that key roles for 
community and public health nurses include taking action as policy advocates, political activists, and in promoting "beneficial social changes that influence the health of groups and populations" (p. 10). This focus of nurses being involved in policy is a key component of the learning taking place in this assignment. The student example in Table 3 illustrates the concept of social justice in providing a curriculum specifically for the identified population of LGBTQ individuals.

\section{Reflection on Teaching and Learning}

One of the opportunities of this activity includes helping students to apply a population perspective when identifying a policy issue relevant to the health of a specific vulnerable group. By communicating closely with students as they develop a specific plan for the Advocacy Assignment, faculty members assist students to move their advocacy from the individual focus to a focus on a population. Based on previous experiences with patient teaching, RN-BSN students often begin this process by identifying an individual or group that is need of health teaching. In order to help students move from the individual or group focus, to one that includes a focus on a specific population as well as a specific policy level issue, faculty members spend time collaborating with students to develop their ideas. For example, one of the students identified an interest in working with Hispanic Americans but did not have a clear idea of the health issue or policy that she wanted to address. With faculty member coaching, she was able to identify a specific issue impacting the health of the community that interested her. With additional collaboration, she was also able to identify key areas of support needed for Diabetes Prevention among Hispanic American High School students. The policy level advocacy needed to carry this out included gaining access to the student population from school officials.

Eide, Hahn, Bayne, Allen, and Swain (2006) acknowledged the greatest challenge in teaching community health nursing is to help students to conceptualize a population or 
community as the client. They suggested that helping students differentiate between populations and health problems and placing a greater emphasis on population assessment and analysis can be a challenge (Eide et al., 2006). To address this challenge, faculty members require that students contact them to get approval for the population that they have chosen as well as the health topic (advocacy), and their proposed audience. This allows for faculty members to assess the student's understanding of the population perspective as well as the specific expectations of the assignment and provide them with meaningful interaction and support.

This activity provides the opportunity for students to develop their advocacy specific to a policy level issue. When students gain approval for their population and advocacy topic, faculty members ask them also to identify a relevant audience. The audience should be a specific local, state, or global group in a position to make decisions on behalf of the population they have identified. This may be related to allocating resources or funding, approving services, implementing practice changes, or agreeing to a collaborative partnership. Some of the examples provided to students in order to help them think critically about policy level changes include a Board of Directors or group of Trustees, the House Committee on Healthcare, the Senate or another group of government officials, a Grant Review Committee, a Committee representing a Public Health Department, a local Foundation, a Tribal Council, a State Board of Nursing, and a School Board. When identifying a relevant audience for their advocacy statement, faculty members provide key questions that challenge students to make realistic decisions about who can make impactful decisions. By engaging in this process, students begin to see the possibilities for how nurses in the community are able to use their knowledge, skills, and experience to influence services and support addressing the needs of vulnerable populations. 


\section{Recommendations}

After carefully evaluating this assignment and comparing it to the expectations for advocacy and leadership in population health and population focused healthcare, the authors strongly recommend integration of learning activities focused on health disparities, social health determinants, and vulnerable populations in baccalaureate programs. It is important that students develop a strong awareness of social issues impacting the health of individuals, families, and populations while also developing their skills for social advocacy and community change.

There are additional opportunities for development within this assignment. Due to the importance of collaboration and developing partnerships within the community, a component of collaboration in the community could be added that requires students to identify and develop a plan for how key partnerships with organizations and coalitions influences healthcare outcomes. Harkness and DeMarco (2012) emphasized that the practice of public health and community health nurses requires a willingness and readiness to collaborate with community members as well as other professionals from varying fields.

Due to the moral and ethical components of delivering nursing care to vulnerable populations in the community, it would be beneficial to include a reflective component to this activity. Critical reflection regarding the needs of vulnerable populations can provide opportunities to enhance awareness and compassion for those who are disadvantaged and underserved. The advantages of reflection being part of this assignment include the opportunity to stimulate critical thinking, the ability to encourage ownership of the learning, and as a way to provide a feedback loop between the teacher and student so that teaching can be modified to enhance learning (Rowles \& Russo, 2009). 
There is an opportunity to have students engage in a live synchronous dialogue instead of using the asynchronous discussion option. The advantage of this is that students need to be well prepared to advocate for and defend their policy as well as answer questions that were posed by their target audience (assigned partner). The ability to articulate and respond in real time would add a sense of urgency as well as prepare students for presenting to a live audience.

For online nursing programs to evolve beyond the mere teaching of the content, attention must be given to fostering an educational approach that uses real-world contexts to facilitate proficiency in oral and written communication and equips students with the skills needed for practice (Culley \& Polyakova-Norwood, 2012, p. 51).

Many aspects of the assignment allow for growth in written communication, however, having a synchronous exchange would address oral communication specifically.

Lastly, there is an opportunity to assess whether the student explored additional avenues for advocacy for vulnerable populations beyond the Advocacy assignment and the Population course. This could be done conducting a survey or reflective activity in the final term of the RNBSN program. It would be valuable to assess if the work done with vulnerable populations had a lasting influence on their professional nursing practice, and if so, what that influence was.

\section{Conclusion}

The Vulnerable Populations Advocacy Assignment provides a meaningful opportunity to develop skills in professional advocacy on behalf of RN-BSN students. The activity emphasizes key curricular concepts of advocacy, leadership, health policy, and vulnerable populations which are integrated throughout the RN-BSN curriculum. In addition, the activity addresses recommendations for nursing practice in the community identified by the American Association 
of Colleges of Nursing (2008), the Quad Council Competencies for Public Health Nurses (2011), and the Institute of Medicine (2010).

\section{References}

American Association of Colleges of Nursing. (2008). The essentials of baccalaureate education for professional nursing practice. Retrieved from http://www.aacn.nche.edu/educationresources/baccessentials08.pdf

American Nurses Association. (2010a). Nursing: Scope and standards of practice (2nd ed.). Silver Spring, MD: ANA.

American Nurses Association. (2010b). Nursing's social policy statement: The essence of the profession. Silver Spring, MD: ANA.

Bailey, D. N. (2010). Healthcare of vulnerable populations: Through the lens of Halldorsdottir's theory. International Journal for Human Caring, 14(3), 54-60.

Blais, K. K. \& Hayes, J. S. (2011). Professional nursing practice: Concepts and perspectives (6th ed.). Upper Saddle River, NJ: Pearson.

Centers for Disease Control and Prevention. (2013). Social Determinants of Health. Retrieved from http://www.cdc.gov/socialdeterminants/FAQ.html

Culley, J. M. \& Polyakova-Norwood, V. (2012). Synchronous online role play for enhancing community, collaboration, and oral presentation proficiency. Nursing Education Perspectives, 33(1), 51-54.

Douglas, M. K., Pierce, J., Rosenkoetter, M., Pacquiao, D., Callister, L., Hattar-Pollara, M., Lauderdale, J., Milstead, J., Nardi, D., \& Purnell, L. (2011). Standards of Practice for 
Culturally Competent Nursing Care: 2011 Update. Journal Of Transcultural Nursing, 22(4), 317-333.

Dorsey, C.J., \& Murdaugh, C.L. (2003). The theory of self-management for vulnerable populations. Journal of Theory Construction \& Testing, 7(2), 43-49.

Eide, P.J., Hahn, L., Bayne, T., Allen, C.B., \& Swain, D. (2006). The population-focused analysis project for teaching community health. Nursing Education Perspectives, 1, 2227.

Giddens, J., Brady, D., Brown, P., Wright, M., Smith, D., \& Harris, J. (2009). A new curriculum for a new era of nursing education. Nursing Education Perspectives, 29(4), 200-204.

Grossman, S. C. \& Valiga, T. M. (2009). The new leadership challenge: Creating the future of nursing ( $3^{\text {rd }}$ ed.). Philadelphia: F.A. Davis.

Harkness, G. A. \& DeMarco, R. F. (2012). Community and public health nursing: Evidence for practice. Philadelphia: Lippincott Williams \& Wilkins.

Hutchins, S., Truman, B., Merlin, T., \& Redd, S. (2009). Protecting vulnerable populations from pandemic influenza in the United States: A strategic imperative. American Journal of Public Health, 99, S243-S248.

Keller, L., Strohschein, S., \& Schaffer, M. (2011). Cornerstones of Public Health Nursing. Public Health Nursing, 28(3), 249-260.

Linfield College. (2013). Vision, Mission, and Philosophy. Retrieved from http://www.linfield.edu/portland/about-portland/mission.html

Pacquiao, D. (2008). Nursing care of vulnerable population using a framework of cultural competence, social justice, and human rights. Contemporary Nurse: A Journal for the Australian Nursing Profession, 28, 189-197. 
Rowles, C.J., \& Russo, B.L. (2009). Strategies to promote critical thinking and active learning. In D. M. Billings \& J. A. Halstead, Teaching in nursing: A guide for faculty (3rd ed.) (pp. 238-261). St. Louis, MO: Saunders Elsevier.

Stanhope, M., \& Lancaster, J. (2012). Public health nursing: Population-centered health care in the community, (8th ed.). Maryland Heights, Missouri: Elsevier Mosby.

Tomajan, K. (January 31, 2012). Advocating for nurses and nursing. OJIN: The Online Journal of Issues in Nursing Vol. 17, No. 1, Manuscript 4. Retrieved from http://nursingworld.org/MainMenuCategories/ANAMarketplace/ANAPeriodicals/OJIN/T ableofContents/Vol-17-2012/No1-Jan-2012/Advocating-for-Nurses.html

Quad Council of Public Health Nursing Organizations. (2011). Quad council competencies for public health nurses. Retrieved from http://www.resourcenter.net/images/ACHNE/Files/QuadCouncilCompetenciesForPublic HealthNurses_Summer2011.pdf 